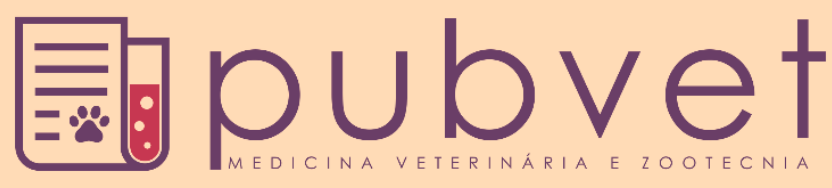

https://doi.org/10.31533/pubvet.v14n01a735.1-8

\title{
Emergência de zoonoses em desastres: Relato de caso de leptospirose em Brumadinho, Minas Gerais
}

\author{
Angela Ramos Silvestrini ${ }^{1 *}$, Antonio Carlos Paes ${ }^{2}{ }^{\ominus}$, Alessandra Marnie Martins Gomes de Castro ${ }^{3 \bullet}$ \\ ${ }^{1}$ Mestranda do Programa de Mestrado Profissional em Saúde Ambiental das Faculdades Metropolitanas Unidas. São Paulo - SP, Brasil. \\ ${ }^{2}$ Pesquisador e Docente do Departamento de Higiene Veterinária e Saúde Pública da Faculdade de Medicina Veterinária e Zootecnia da \\ Universidade Estadual Paulista. Botucatu - SP, Brasil. \\ ${ }^{3}$ Pesquisadora e Docente do Curso de Medicina Veterinária e Mestrado Profissional em Saúde Ambiental das Faculdades Metropolitanas \\ Unidas. São Paulo - SP, Brasil. \\ *Autor para correspondência, E-mail: alessandramarnie@gmail.com
}

Resumo. A ocorrência de desastres tecnológicos, como os que são provenientes de rompimento de barragens, e cujas consequências no ambiente são de caráter permanente, como a destruição de ecossistemas e a degradação do solo, chamam a atenção para a ocorrência de transmissão de zoonoses, sendo a mais destacada a leptospirose. A partir de um relato de caso de um cão adotado infectado por leptospirose após o rompimento da barragem de rejeitos de minério de ferro em Brumadinho, Minas Gerais, o presente artigo busca discutir de maneira crítica as práticas humanitárias de adoção de animais em estado de vulnerabilidade sem os devidos cuidados de saúde iniciais, suscetíveis a transmissão de doenças.

Palavras chave: Adoção de animais, desastres tecnológicos, leptospirose

\section{Emergence of zoonoses in disasters: A case report of leptospirosis in Brumadinho, Minas Gerais}

\begin{abstract}
The occurrence of technological disasters, such as those that come from dam ruptures and whose consequences on the environment are permanent, such as the destruction of ecosystems and soil degradation, draw attention to the occurrence of zoonoses transmission, being the most leptospirosis. From a case report of an adopted dog infected with leptospirosis after the rupture of the iron ore tailings dam in Brumadinho, Minas Gerais, the present article seeks to critically discuss the humanitarian practices of adopting animals in the state of vulnerability without the due initial health care, susceptible to the transmission of diseases.
\end{abstract}

Keywords: Animals adoption, technological disasters, leptospirosis

\section{Zoonosis en desastres: Reporte de un caso de leptospirosis en Brumadinho, Minas Gerais}

Resumen. La ocurrencia de desastres tecnológicos, como los derivados de la ruptura de represas, y cuyas consecuencias sobre el medio ambiente son de carácter permanente, como la destrucción de ecosistemas y la degradación de suelos, llaman la atención sobre la casuística de la transmisión de zoonosis, siendo la leptospirosis la más destacada. Basado en un reporte de caso de un perro adoptado infectado con leptospirosis luego de la ruptura de la represa de mineral de hierro en Brumadinho, Minas Gerais, este artículo busca discutir críticamente las prácticas humanitarias de adoptar animales en estado vulnerable. sin la atención médica inicial adecuada, susceptible de transmisión de enfermedades.

Palabras clave: Adopción de animales, desastres tecnológicos, leptospirosis 


\section{Introdução}

O rompimento da barragem de rejeitos de minério de ferro ocorrido no dia vinte e cinco de janeiro de 2019 na cidade de Brumadinho, localizada no estado de Minas Gerais, trouxe um importante alerta às autoridades de saúde pública, não somente pelo fato do desastre trazer danos ambientais permanentes à região, como também por favorecer um ambiente propício ao desenvolvimento de zoonoses, como a leptospirose. Naquela data houve o rompimento de uma barragem de rejeitos de minério de ferro pertencente à mineradora Vale S.A. (Figura 1). Os rejeitos da Barragem I, localizada no complexo minerário Córrego do Feijão, na cidade de Brumadinho, em Minas Gerais, acabaram por transbordar outras duas barragens, que escoaram por uma grande extensão de terras da cidade, até serem drenados pelo rio Paraopeba (Pereira et al., 2019).

De maneira geral, a lama que cobriu grande extensão de terras trouxe, além da questão da contaminação do solo, diversas consequências no que diz respeito às condições de saúde. $\mathrm{O}$ comprometimento dos solos agrícolas, das fontes de água e das interações ecossistêmicas instaladas na região fez com que diversos relacionamentos dos humanos com o ambiente fossem prejudicados, incluindo a produção de alimentos e das práticas agrícolas e a condição dos recursos hídricos que foram afetados (Carvalho et al., 2017; Dias et al., 2018).

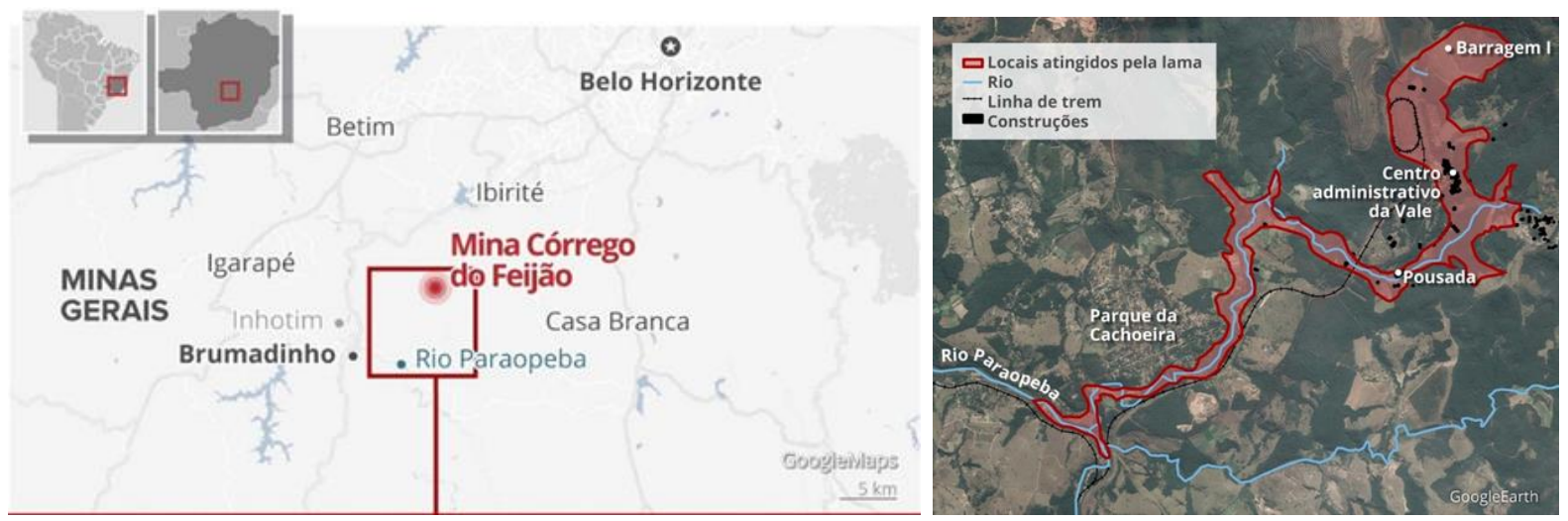

Figura 1. Localização da mina Córrego do Feijão e das demais localidades atingidas pelo rompimento da Barragem I, em Brumadinho. Fonte: https://g1.globo.com/mg/minas-gerais/noticia/2019/01/27/tragedia-em-brumadinho-o-caminho-dalama.ghtml. Acesso em: 28 de jun. de 2019.

Especialmente no que diz respeito à ocorrência do desastre tecnológico em Brumadinho, a inundação provocada pela avalanche de lama contida na barragem rompida, além de causar a morte imediata de pessoas e devastação ambiental, pode aumentar a morbimortalidade de algumas doenças e agravos neste contexto, algumas zoonoses recebem ambiente propício para seu desenvolvimento como a expansão de animais sinantrópicos e a proliferação de agentes infecciosos (Romão et al., 2019).

O comprometimento do rompimento da barragem abrange também a vulnerabilidade dos animais. De acordo com Irvine (2009), os animais possuem vulnerabilidade com características variáveis, pois estão sujeitos a diferentes riscos e possuem, em contrapartida, diferentes habilidades para lidar com situações, assim como maior ou menor controle sobre seus ambientes. No caso dos animais de estimação, que foram domesticados ao longo do tempo, essa relação com o homem resultou na sua sobrevivência. $\mathrm{O}$ fato de serem vulneráveis faz com que em situações críticas como, por exemplo, em desastres, muitos se percam de seus tutores e acabem morrendo em decorrência de ferimentos, inanição, desidratação ou doenças (Antonio \& Valencio, 2016).

Austin (2013) propôs um roteiro de plano de emergência para atender às necessidades da população animal, que inclui um planejamento adequado baseado em informações confiáveis e uma legislação compatível. Além disso, ressalta a necessidade da especificação dos recursos a serem utilizados e colaboração da comunidade e dela com a as demais instituições da sociedade civil. Por sua vez, Waugh Junior \& Streib (2006) destacam a importância da colaboração em rede em eventos de desastres, o que inclui a participação social no planejamento e em exercícios de treinamento. 
Para Leonard \& Scammon (2007), a preocupação com os animais em meio a desastres pode ser dividida em quatro grandes áreas: as considerações de caráter econômico, questões de saúde pública, o bem-estar emocional do homem e o próprio bem-estar dos animais de estimação. Muito além do impacto econômico e do custo emocional que os desastres que atingem os animais podem causar nos seres humanos, as questões de saúde pública também têm sido uma grande preocupação em relação aos animais, pois em desastres os animais doentes e mortos são criadouros de bactérias, vírus e parasitas e podem causar surtos de doenças infecciosas. Dentre elas, a leptospirose é uma zoonose infectocontagiosa de caráter agudo ou crônico causada por bactérias espiroquetas do gênero Leptospira spp. (Vincent et al., 2019). Geograficamente, possuem distribuição mundial e potencial de acometer várias espécies de animais domésticos, silvestres e roedores. Entre os animais domésticos, com destaque nas áreas urbanas, os cães estão entre as principais fontes de infecção para os seres humanos (Greene et al., 1993; Lilenbaum et al., 2005).

As leptospiras são espiroquetas extremamente móveis e flexíveis, com forma helicoidal, com extremidades encurvadas em forma de ganchos típicos, que apresentam dois flagelos periplasmáticos axiais. Se movimentam por rotação e seu tamanho varia entre 0,1 a $0,15 \mu \mathrm{m}$ de espessura por 6,0 a $12,0 \mu \mathrm{m}$ de comprimento (Bharti et al., 2003; Solomon Faine, 1999; Ritchie \& Ellinghausen, 1965). São bactérias obrigatoriamente aeróbias e sua persistência no ambiente, quando não estão em estado de parasitismo, se dá na presença de umidade e temperatura que varia entre $28^{\circ} \mathrm{C}$ a $32^{\circ} \mathrm{C}$ e de um $\mathrm{pH}$ do meio de caráter neutro ou levemente alcalino, que varia em torno de 7,2 a 7,6. Além disso, observa-se a reprodução apenas no organismo hospedeiro por meio de fissão binária (Faine, 2000; Levett \& Haake, 2010). Nesse aspecto, o desastre ocorrido em Brumadinho parece ter criado condições para sua manutenção no ambiente, uma vez que a lama propiciou ambiente úmido, com características químicas neutras ou levemente alcalinas ideais para sobrevida das Leptospira spp. (Faine, 2000; Levett \& Haake, 2010).

O objetivo do presente artigo foi relatar um caso de infecção por leptospirose de um cão adotado advindo da cidade de Brumadinho (MG), logo após a ocorrência do desastre. Além disso, o artigo atenta para os devidos cuidados de saúde com as práticas humanitárias, principalmente no que diz respeito às práticas de prevenção a doenças após a adoção de animais vulneráveis em ambientes acometidos por desastres.

\section{Relato de caso}

Uma cadela, sem raça definida, de cinco meses de idade deu entrada na Clínica Veterinária Guaipá, localizada na cidade de São Paulo, no dia vinte e dois de fevereiro de 2019, com o histórico de ter sido resgatada por uma ONG (Organização Não Governamental) na cidade de Brumadinho, após o desastre. Nesta ONG foi realizado o procedimento de OSH (ováriohisterectomia). Trazida a São Paulo e adotada por uma família, o animal realizou exames de rotina durante o qual apresentou prostração e apatia ao exame físico. As mucosas apresentavam-se normocoradas e sua temperatura era de $39,3^{\circ} \mathrm{C}$. Os linfonodos se apresentavam normais e com sensibilidade abdominal.

No dia vinte e dois de fevereiro de 2019 foi coletada uma amostra de sangue para execução de hemograma, o qual apontou que o animal possuía anemia normocítica e normocrômica (anemia inflamatória) com leucocitose por neutrofilia (Tabela 1). Desta forma, dada a presença de uma infecção com característica bacteriana (pela resposta neutrofílica), foi prescrito o antibiótico Cloridrato de Doxiciclina na dose de $5 \mathrm{mg} / \mathrm{kg}$ a cada doze horas durante vinte e oito dias.

Com apenas dois dias de terapia, no dia vinte e cinco de fevereiro de 2019 foi coletado um novo hemograma controle, além dos índices bioquímicos da ureia e creatinina. Os resultados apontaram a permanência da anemia inflamatória com melhora da resposta leucocitária. Com relação aos índices bioquímicos, estes apresentaram valores dentro dos intervalos de normalidade (Tabela 1).

De acordo com Hagiwara et al. (2015), ao estarmos na presença de um cão com história clínica e exame físico compatíveis com a leptospirose, faz-se necessário o exame laboratorial. No relato em questão, embora os índices bioquímicos estivessem dentro da normalidade, o resultado do hemograma que indicou um quadro inflamatório somado ao fato de ter sido resgatado após o desastre de Brumadinho fez crescer a suspeita de uma infecção por Leptospira spp. Conforme Kogika et al. (1990), consultas realizadas com infectologistas identificaram o surto da leptospirose como uma possível doença a ser disseminada com o conteúdo da lama espalhada pela cidade após o rompimento da barragem. Além 
disso, protocolos de segurança que incluíram a aplicação de antibiótico às equipes de resgate foram adotados, fatos que reforçaram a necessidade do teste para a leptospirose no cão.

Em vinte e sete de fevereiro de 2019 foi coletado sangue para realizar o teste de soro aglutinação microscópica e Reação em Cadeia pela Polimerase (PCR do inglês - Polymerase Chain Reaction) para identificação de Leptospira spp. O resultado do soro aglutinação microscópica foi que o animal apresentou um título de 400 para o sorovar Copenhageni, do soro grupo Icterohaemorrhagiae e para o sorovar Tarassovi (Tabela 2). Segundo Alves et al. (2000), os sorovares mais comuns associados ao quadro de leptospirose em cães pertencem ao sorogrupo Icterohaemorrhagiae, o que poderia indicar que o cão foi infectado pelo sorovar Copenhageni.

O resultado da PCR foi negativo. A ausência de ácido nucleico do agente no sangue indica que o animal já não estava mais em leptospiremia no momento de coleta.

No dia nove de março de 2019 foi realizado um novo hemograma, cujos resultados indicaram que o animal ainda permanecia com anemia inflamatória, no entanto com adequado padrão da resposta leucocitária.

Por fim, em vinte e sete de março de 2019, uma nova sorologia para a leptospirose foi realizada, cujo resultado não indicou a presença de reatividade, o que significa considerar que o tratamento instituído para leptospirose foi bem-sucedido (Tabela 2).

Tabela 1. Resultados dos hemogramas e exame bioquímico

\begin{tabular}{|c|c|c|c|}
\hline \multirow[b]{2}{*}{ Eritrograma } & \multicolumn{3}{|c|}{ Data da coleta } \\
\hline & $22 / 02 / 19$ & 25/02/19 & $09 / 03 / 19$ \\
\hline Hemácias $(\mu \mathrm{l})$ & 3,02 & 3,6 & 4,89 \\
\hline Hemoglobina (g/dL) & 7 & 8,3 & 11,3 \\
\hline Hematócrito $(\%)$ & 21 & 25 & 34 \\
\hline $\operatorname{VCM}\left(\mu^{3}\right)$ & 69,54 & 69,44 & 69,53 \\
\hline HCM (pg) & 23,18 & 23,06 & 23,11 \\
\hline $\mathrm{CHCM}(\%)$ & 33,33 & 33,20 & 33,24 \\
\hline PT (Plasma) (g/dL) & 9 & 8,8 & 6,4 \\
\hline Plaquetas $\left(\mathrm{mil} / \mathrm{mm}^{3}\right)$ & 200 & 340 & 240 \\
\hline Macroplaquetas & Discreta & Discreta & Discreta \\
\hline Agregados plaquetários & Moderada & Moderada & Moderada \\
\hline Demais Observações & & $\begin{array}{c}\text { Discreta } \\
\text { anisocitose e } \\
\text { policromasia }\end{array}$ & $\begin{array}{c}\text { Discreta } \\
\text { anisocitose } \\
\text { policromasi }\end{array}$ \\
\hline \multicolumn{4}{|l|}{ Leucograma } \\
\hline Leucócitos $(/ \mu \mathrm{l})$ & 25830 & 8190 & 11130 \\
\hline Mielócitos $(/ \mu 1)$ & 0 & 0 & 0 \\
\hline Metamielócitos $(/ \mu \mathrm{l})$ & 0 & 0 & 0 \\
\hline Bastonetes $(/ \mu 1)$ & 0 & 0 & 0 \\
\hline Segmentados $(/ \mu 1)$ & 23505,3 & 6470,1 & 7791 \\
\hline Linfócitos $(/ \mu \mathrm{l})$ & 1808,1 & 1474,2 & 2226 \\
\hline Monócitos $(/ \mu 1)$ & 516,6 & 245,7 & 222,6 \\
\hline Eosinófilos $(/ \mu 1)$ & 0 & 0 & 890,4 \\
\hline Basófilos $(/ \mu 1)$ & 0 & 0 & 0 \\
\hline $\begin{array}{l}\text { Neutrófilos } \\
\text { Hiposegmentados }\end{array}$ & Discreta & Discreta & Discreta \\
\hline Linfócitos Reativos & - & Discreta & - \\
\hline \multicolumn{4}{|l|}{ Exame bioquímico } \\
\hline Ureia (mg/dL) & - & 34,5 & \\
\hline Creatinina (mg/dL) & - & 0,82 & \\
\hline
\end{tabular}

Tabela 2. Resultados das sorologias para leptospirose e exame para PCR

\begin{tabular}{lcc}
\hline Sorologia para & \multicolumn{2}{c}{ Data da coleta } \\
\cline { 2 - 3 } Leptospirose & $27 / 02 / 19$ & $27 / 03 / 19$ \\
\hline Resultado & Reagente & Não Reagente \\
Sorovares & Título & \\
Icterohaemorrhagiae & 100 & \\
Canicola & 200 & \\
Pyrogenes & 100 & \\
Tarassovi & 400 & \\
Pomona & 100 & \\
Copenhageni & 400 & \\
Cynopteri & 200 & \\
Material Utilizado & Soro Sanguíneo & Soro Sanguíneo \\
\hline \multirow{2}{*}{ Método Utilizado } & Soroaglutinação & Soroaglutinação \\
& Microscópica & Microscópica \\
\hline Exame para PCR & & \\
Material & Sangue Total com & - \\
PCR para & EDTA e URINA & - \\
Conclusão & Leptospira & interrogans \\
\hline
\end{tabular}

\section{Discussão}

A partir do exame clínico, os dados de anamnese e dos resultados dos exames laboratoriais, o diagnóstico de leptospirose foi estabelecido. Soma-se a isso o histórico do animal, por ser oriundo de uma área onde havia corrido um desastre envolvendo o rompimento de barragem com despejo de um volume muito grande de lama de rejeitos e comprometimento de recursos hídricos, o que possibilita a 
criação de condições ambientais que favorecem a emergência e manutenção de leptospiras (Romão et al., 2019), fato portanto que auxiliou a direcionar a suspeita clínica.

A soro aglutinação positiva confirmou a suspeita clínica e auxiliou no direcionamento do tratamento e seu êxito. O resultado mostrou que o animal foi exposto ao sorovar Copenhageni, do sorogrupo Icterohaemorrhagiae, com título de 400. No Brasil, os casos mais graves de leptospirose estão relacionados com os sorovares Icterohaemorrhagiae e Copenhageni (BRASIL, 2014). No meio urbano, conforme estudo de Adler \& Moctezuma (2010), o principal reservatório de Leptospira spp. é o rato, mais especificamente o Rattus norvegicus, que hospeda a bactéria de maneira permanente, com destaque para o sorogrupo Icterohaemorrhagiae, sendo capaz de eliminar de forma intermitente e por longos períodos pela urina. Entre os animais domésticos, segundo Fernandes et al. (2013), o cão desempenha grande importância na transmissão ao homem dada sua estreita relação de proximidade, pois atua como fonte de infecção pela excreção de leptospiras pela urina por longos períodos. Por fim, o contato indireto com a água ou solo contaminado por leptospiras, especialmente em situações de desastres como o de Brumadinho, também atuam como vias de transmissão comum para os seres humanos.

No que diz respeito a prevalência, o sorovar Canicola é reconhecidamente o mais encontrado nos cães (Coiro et al., 2011; Dreer et al., 2013; Fontes et al., 2013; Mascolli et al., 2016; Morikawa et al., 2015; Silva et al., 2016). Megid et al. (2016), também destaca o predomínio do sorovar Icterohaemorrhagiae nos inquéritos sorológicos realizados em áreas urbanas no Brasil, porém com certo aumento da incidência de outros sorovares. Nesse sentido, conforme defende o autor, o aumento de uma ocorrência relativamente mais diversa de sorovares pode ter justificativa no controle da doença com a utilização de vacinas que contêm os sorovares clássicos (Icterohaemorrhagiae e Canicola), além do contato direto ou indireto dos cães com outras espécies domésticas ou silvestres. Com isso, além do incentivo à prática da vacinação canina, faz-se necessária a inclusão de novos sorovares que visam o desenvolvimento de vacinas mais efetivas.

A PCR negativa não exclui a infecção, indica que o animal não está em leptospiremia no momento da coleta. De fato, em se tratando da leptospirose, dada a penetração do agente pela pele ou mucosas (nasais, orais ou conjuntivais), as leptospiras já podem ser encontradas na circulação sanguínea e sua disseminação ocorre em vários tecidos, o que inclui o rim, baço, fígado, sistema nervoso central, olhos e trato genital, tendo o período de leptospiremia que pode persistir em até dez dias. A resposta imunológica para esta infecção ocorre em cerca de sete a oito dias após a infecção (Hagiwara et al., 2015).

O diagnóstico definitivo da leptospirose, seguindo Van de Maele et al. (2008), baseia-se na detecção de anticorpos séricos ou na detecção de leptospiras em materiais clínicos como por exemplo a urina, o sangue e o líquor. Conforme defende Charello et al. (2006), a PCR é um método mais sensível no diagnóstico precoce e crônico da leptospirose quando se compara ao teste de soro aglutinação microscópica, pois a sorologia negativa não descarta a fase hiperaguda ou leptospirúrica da doença. Mas, uma limitação encontrada no diagnóstico baseado na PCR é sua incapacidade de identificar o sorovar infectante, fato que sustentou a não utilização da PCR nos estágios iniciais do atendimento.

No caso exposto, para soros pareados o intervalo de trinta dias mostra-se longo, sendo o correto a realização de coleta de uma segunda amostra entre dez a quinze dias após a coleta da primeira. Consequentemente, faz-se necessária a realização da diferenciação entre a chamada "cicatriz" sorológica, anticorpo devido a uma exposição antiga ou vacinação ou efeito do tratamento com o antibiótico que determinou a queda do título de anticorpo.

Em uma infecção ativa, mesmo com o tratamento, depois de transcorrido trinta dias ainda deveria ocorrer resultado na sorologia com títulos decrescentes. O que não foi levado em consideração neste relato é que existe a possibilidade de ter persistido a presença de leptospiras nos túbulos renais com sorologia negativa. Neste caso, o correto procedimento deveria incluir um exame da função renal pelos índices bioquímicos de ureia e creatinina. Segundo Miotto et al. (2018), pode-se adotar três tipos de protocolos para o controle da enfermidade, que podem incluir (1) uma dose subcutânea única de Estreptomicina $25 \mathrm{mg} / \mathrm{kg}$, (2) Cloridrato de Doxiciclina oral $4 \mathrm{mg} / \mathrm{kg}$ por 14 dias ou (3) uma dose subcutânea única de Ceftriaxona $30 \mathrm{mg} / \mathrm{kg}$.

A leptospirose constitui um grave problema a saúde pública, pois os animais podem ser portadores assintomáticos, e atuarem como reservatório. Além disso, como sustentado por Fernandes et al. (2013), 
por ser uma enfermidade endêmica que ocorre em toda a extensão no Brasil, acaba por ser uma zoonose que reflete diretamente na economia do país. Nesse sentido, além das necessárias medidas de higiene e controle dos roedores, a vacinação dos animais contendo sorovares específicos de cada região contribuem para a profilaxia da doença.

\section{Conclusão}

Dentro do contexto da ocorrência de desastres, especialmente no que diz respeito a desastres tecnológicos com impactos importantes no ambiente, a preocupação com o bem-estar animal mostra-se ao mesmo tempo recente e, de certa forma, ainda existem pontos a serem aprimorados, pois existem falhas relevantes nos mecanismos de proteção aos animais, sobretudo com relação aos animais em estado de vulnerabilidade. Entretanto, surgem novas correntes que buscam a defesa e auxílio a esses animais, com destaque para as práticas humanitárias realizadas pelas ONG's.

O resgate humanitário do cão e a sua precoce inserção na vivência com a comunidade sem o completo conhecimento e acompanhamento das condições clínicas do animal, como por exemplo a prática de uma rotina de exames para detecção de possíveis infecções que possam ser propagadas entre demais animais e para seus novos donos surge como pré-requisito para uma prática ideal e saudável do resgate humanitário de animais vulneráveis do ponto de vista da saúde pública. Além disso, dada a diminuição das fronteiras geográficas entre diferentes localidades do planeta com as novas tecnologias disponíveis, torna um caso de uma zoonose (como a leptospirose no relato de caso) local a níveis nacionais e, em última consequência, níveis mundiais, que age como potencializadora na propagação de doenças.

No contexto de Saúde Única, os cães são bons sentinelas na detecção da presença de leptospirose no ambiente e podem ser considerados como primordiais para o entendimento da epidemiologia da doença. No que se refere a população de cães em situações de desastre, é importante o diagnóstico precoce e o consequente tratamento, minimizando as chances de infecção humana.

\section{Referências}

Adler, B., \& Moctezuma, A. P. (2010). Leptospira and leptospirosis. Veterinary Microbiology, 140(34), 287-296. DOI: https://doi.org/10.1007/978-1-0716-0459-5_24

Alves, C. J., Andrade, J. S. L., Vasconcellos, S. A., Morais, Z. M., Azevedo, S. S., \& Santos, F. A. (2000). Avaliação dos níveis de aglutininas anti-leptospira em cães no município de Patos-PB, Brasil. Revista Brasileira de Ciência Veterinária, 7(1), 17-21. DOI: https://doi.org/10.4322/rbcv.2015.168

Antonio, L. S., \& Valencio, N. (2016). Animais de estimação em contexto de desastres: desafios de (des) proteção. Desenvolvimento e Meio Ambiente, 38, 741-767. DOI: https://doi.org/10.5380/dma.v38i0.44559

Austin, J. J. (2013). Shelter from the storm: Companion animal emergency planning in nine states. Journal of Sociology and Social Welfare, 40, 185-210.

Bharti, A. R., Nally, J. E., Ricaldi, J. N., Matthias, M. A., Diaz, M. M., Lovett, M. A., Levett, P. N., Gilman, R. H., Willig, M. R., \& Gotuzzo, E. (2003). Leptospirosis: a zoonotic disease of global importance. The Lancet Infectious Diseases, 3(12), 757-771. DOI: https://doi.org/10.1016/S14733099(03)00830-2

BRASIL. Ministério da Saúde. Guia de Vigilância em Saúde. 1. ed. Brasília, DF: Ministério da Saúde, 2014.

Carvalho, M. S., Ribeiro, K. D., Moreira, R. M., \& Almeida, A. M. (2017). Concentração de metais no rio Doce em Mariana, Minas Gerais, Brasil. Acta Brasiliensis, 1(3), 37-41. DOI: https://doi.org/10.22571/actabra13201758

Charello, T. (2006). PCR no diagnóstico da leptospirose canina em presença de sorologia negativa. In: 14 EVINCI - Evento de iniciação científica, 2006, Curitiba. Anais... Curitiba, UFPR, p. 139.

Coiro, C. J., Langoni, H., Silva, R. C., \& Ullmann, L. S. (2011). Fatores de risco para leptospirose, leishmaniose, neosporose e toxoplasmose em cães domiciliados e peridomíciliados em Botucatu-SP. Veterinária e Zootecnia, 18(3), 393-407.

Dias, C. A., Costa, A. S. V., Guedes, G. R., Umbelino, G. J. M., Sousa, L. G., Alves, J. H., \& Silva, T. G. M. (2018). Impactos do rompimento da barragem de Mariana na qualidade da água do rio Doce. 
Revista Espinhaço| UFVJM, 7(1), 21-35.

Dreer, M. K. P., Gonçalves, D. D., Caetano, I. C. S., Gerônimo, E., Menegas, P. H., Bergo, D., LopesMori, F. M. R., Benitez, A., Freitas, J. C., \& Evers, F. (2013). Toxoplasmosis, leptospirosis and brucellosis in stray dogs housed at the shelter in Umuarama municipality, Paraná, Brazil. Journal of Venomous Animals and Toxins Including Tropical Diseases, 19(1), 1-5. DOI: https://doi.org/10.1186/1678-9199-19-23

Faine, S. (2000). Guideline for control of leptospirosis. World Health Organization Geneva, 67, 129.

Faine, Solomon. (1999). Leptospira and leptospirosis. CRC Press Inc.

Fernandes, A. R. F., Fernandes, A. G., Araújo, V. J. A., Higino, S. S. S., Silva, M. L. C. R., Alves, C. J., \& Azevedo, S. S. (2013). Soroepidemiologia da leptospirose canina na região metropolitana de Natal, estado do Rio Grande do Norte. Brazilian Journal of Veterinary Research and Animal Science, 50(3), 226-232. DOI: https://doi.org/10.11606/issn.1678-4456.v50i3p226-232

Fontes, A. M. M., Rufino, C. A., Assunção, T. M., Silva, E. S. S., Belarmino, D. A., Santos, D. G., Lopes, P. D., \& Barbudo Filho, J. (2013). Soroprevalência de leptospirose em cães no município de Andradina/SP. Ciência Agrária e Saúde, 9, 21-25.

Greene, C. E., Samperio, J. O., \& Gómez, J. P. (1993). Enfermedades infecciosas: Perros y gatos. Editora Interamericana.

Hagiwara, M. K., Miotto, B. A., \& Kogika, M. M. . (2015). Leptospirose. In M. M. Jericó, J. P. A. Neto, \& M. M. Kogika (Eds.), Tratado de medicina interna de cães e gatos (pp. 2678-2708). Roca.

Irvine, L. (2009). Conclusion: Noah's Task. In L. Irvine (Ed.), Filling the Ark: Animal welfare in disasters. Temple University Press.

Kogika, M. M., Hagiwara, M. K., \& Mirandola, R. M. S. (1990). Alterações bioquímicas na leptospirose canina. Brazilian Journal of Veterinary Research and Animal Science, 27(2), 177-182. DOI: https://doi.org/10.11606/issn.0000-0000.272177-182

Leonard, H. A., \& Scammon, D. L. (2007). No pet left behind: Accommodating pets in emergency planning. Journal of Public Policy \& Marketing, 26(1), 49-53. DOI: https://doi.org/10.1509/jppm.26.1.49

Levett, P. N., \& Haake, D. A. (2010). Leptospira species (leptospirosis). Principles and Practice of Infectious Diseases, 997-980. DOI: https://doi.org/10.1016/B978-0-323-40181-4.00184-5

Lilenbaum, W., Varges, R., Moraes, I. A., Ferreira, A. M. R., \& Pissinatti, A. (2005). Leptospiral antibodies in captive lion tamarins (Leontopithecus sp) in Brazil. The Veterinary Journal, 169(3), 462-464. DOI: https://doi.org/10.1016/j.tvj1.2004.03.015

Mascolli, R., Soto, F. R. M., Bernardi, F., Ito, F. H., Pinheiro, S. R., Guilloux, A. G. A., Azevedo, S. S., Fernandes, A. R. F., Keid, L. B., \& Morais, Z. M. (2016). Prevalência e fatores de risco para a leptospirose e brucelose na população canina da Estância Turística de Ibiúna, São Paulo, Brasil. Arquivos Do Instituto Biológico, 83, 1-7. DOI: https://doi.org/10.1590/1808-1657000842014

Megid, J., Ribeiro, M. G., \& Paes, A. C. (2016). Doenças infecciosas em animais de produção e de companhia. Roca.

Miotto, B. A., Guilloux, A. G. A., Tozzi, B. F., Moreno, L. Z., Hora, A. S., Dias, R. A., Heinemann, M. B., Moreno, A. M., Filho, A. F. S., \& Lilenbaum, W. (2018). Prospective study of canine leptospirosis in shelter and stray dog populations: Identification of chronic carriers and different Leptospira species infecting dogs. PloS One, 13(7), e0200384. DOI: https://doi.org/10.1371/journal.pone.0200384

Morikawa, V. M., Bier, D., Pellizzaro, M., Ullmann, L. S., Paploski, I. A. D., Kikuti, M., Langoni, H., Biondo, A. W., \& Molento, M. B. (2015). Seroprevalence and seroincidence of Leptospira infection in dogs during a one-year period in an endemic urban area in Southern Brazil. Revista Da Sociedade Brasileira de Medicina Tropical, 48(1), 50-55. DOI: https://doi.org/10.1590/0037-8682-0213-2014

Pereira, L. F., Cruz, G. B., \& Guimarães, R. M. F. (2019). Impactos do rompimento da barragem de rejeitos de Brumadinho, Brasil: uma análise baseada nas mudanças de cobertura da terra. Journal of Environmental Analysis and Progress, 4(2), 122-129. DOI: https://doi.org/10.24221/jeap.4.2.2019.2373.122-129 
Ritchie, A. E., \& Ellinghausen, H. C. (1965). Electron Microscopy of Leptospires I. Anatomical Features of Leptospira pomona. Journal of Bacteriology, 89(1), 223-233. DOI: https://doi.org/10.1128/jb.89.1.223-233.1965

Romão, A., Froes, C., Barcellos, C., Silva, D. X., Saldanha, R., Gracie, R., \& Pascoal, V. (2019). Avaliação dos impactos sobre a saúde do desastre da mineração da Vale (Brumadinho, MG). In Brasil: Ministério da Saúde.

Silva, R. C., Lima, V. Y., Silva, A. V., Souza, L. C., \& Langoni, H. (2016). Seroepidemiological survey for canine leptospirosis in the coast of São Paulo State, Brazil. Veterinária e Zootecnia, 23(3), 495-503.

Van de Maele, I., Claus, A., Haesebrouck, F., \& Daminet, S. (2008). Leptospirosis in dogs: a review with emphasis on clinical aspects. Veterinary Record, 163(14), 409-413. DOI: https://doi.org/10.1136/vr.163.14.409

Vincent, A. T., Schiettekatte, O., Goarant, C., Neela, V. K., Bernet, E., Thibeaux, R., Ismail, N., Mohd Khalid, M. K. N., Amran, F., \& Masuzawa, T. (2019). Revisiting the taxonomy and evolution of pathogenicity of the genus Leptospira through the prism of genomics. PLoS Neglected Tropical Diseases, 13(5), e0007270. DOI: https://doi.org/10.1371/journal.pntd.0007270

Waugh Junior, W. L., \& Streib, G. (2006). Collaboration and leadership for effective emergency management. Public Administration Review, 66, 131-140. DOI: https://doi.org/10.1111/j.1540$\underline{6210.2006 .00673 . x}$

\section{Histórico do artigo:}

Recebido: 25 de julho de 2020

Aprovado: 28 de agosto de 2020.

Disponível online: 27 de novembro de 2020.
Licenciamento: Este artigo é publicado na modalidade Acesso Aberto sob a licença Creative Commons Atribuição 4.0 (CC-BY 4.0), a qual permite uso irrestrito, distribuição, reprodução em qualquer meio, desde que o autor e a fonte sejam devidamente creditados. 